\title{
An NDEA Model as Policy Tool to Support Managerial Decisions
}

\author{
Claudio Pinto ${ }^{1}$ \\ ${ }^{1}$ University of Salerno, Fisciano (SA), Via Giovanni Paolo II, Italy \\ Correspondence: Claudio Pinto, University of Salerno, 84084,Fisciano (SA), Via Giovanni Paolo II, Italy. \\ Received: March 18, 2020 \\ Accepted: April 14, 2020 \\ Online Published: April 20, 2020 \\ doi:10.5430/ijba.v11n3p21 \\ URL: https://doi.org/10.5430/ijba.v11n3p21
}

\begin{abstract}
Data Envelopment Analysis (DEA) is a non-parametric frontier approach used both to model production processes and/or production organisations of goods and services (public and private) as inputs/output systems and to measure their relative efficiency. However, in addition to being an instrument for measuring economic performances, the DEA is also used in its multiplicative version as a policy tool to support managerial decisions for the pursuit of competing objectives. Based on the data, the DEA offers an answer to the pursuit of competing objectives by placing it as a trade-off and calculating the optimal weights associated with each of them. Here, we will address two questions: 1) how to overcome the DEA modelling of decision-making units as "black boxes" that use inputs to be translated into outputs to taking into account the operations/stages involved in this transformation process, and 2) how to use the Network Data Envelopment Analysis (NDEA) approach as a policy tool. In particular, we will propose a way to use a relational NDEA model as a policy tool by exploiting the possibility of making assumptions about the model variables. In our opinion, compared to the standard DEA, the advantage of using the NDEA as a policy tool is that the policy objectives (in this case organisational) can also be disaggregated at the sub-process level. In particular, we will propose to translate the system of organisational objectives into an NDEA model as a mix of "discretionary/non-discretionary" assumptions about the variables of the model itself. To clarify our proposal, we will then develop an application in the public health services sector.
\end{abstract}

Keywords: network DEA, performances management, organizational policy, decision process, external factor effects

\section{Introduction}

In this paper, we will deal with the use of non-parametric frontier models for measuring relative efficiency as a policy tool when they are applied to production processes (but in general to generic decision-making units), which are modelled as networks of sub-processes/organisational parts interconnected with each other. Our attention will, therefore, be focused on the organisational policy level. In particular, we will refer to a variant (advancement) of the Data Envelopment Analysis (DEA) methodology which goes under the name of "relational Network Data Envelopment Analysis (NDEA)" introduced for the first time from [ (Kao, 2009(a))]. This approach allows measuring the relative efficiency of decision-making units and their parts when they are modelled as networks of interconnected parts. To show the use of this approach as a policy tool, we will refer to an NDEA model for a simple production process with only two subprocesses (for a more complete classification of this modelling, see [ (Castelli, Pesenti, \& Ukovich, 2010) and (Kao, 2014)] on which we will impose a "discretionary-non-discretionary" on the variables of the model itself. We note that some scholars such as [ (Smith \& Street, 2005)] have addressed the topic (see Note 1), but their arguments refer to DEA and not to NDEA. The latter two authors wonder if the DEA models are ready to be used as policy tools (see Note 2) Among other things, these authors conclude that for simple and well-defined production processes, as well as supported by good data, these models can be considered as a policy tool because some public regulators use them as a tool to influence real economic behavior of organisations that produce and/or distribute public (and private) goods and services. Among the controversial areas in measuring efficiency with these models, these two authors include the following: 1) the construction of the model (i.e., how accurately it can model real production processes), and 2) how the question of pursuit of objectives with this methodology (other issues (see Note 3) are however treated) underlining that in the DEA context the issue is treated in the form of a trade-off between competing objectives and is resolved by calculating the optimal weights associated with them on the basis of data (see Note 4). Among the reasons for treating policy preferences in efficiency measurements (we point out that the issue has also been of interest to other scholars as [ (Shrime, Mukhopadhyay, \& 
Alkirea, 2018) other than (Smith \& Street, 2005)] instead emphasise that policymakers count among the objectives to be pursued that of using efficiently the public resources destined for the production and then distribution of public services, and that the issue is relevant as public services have the clear role of promoting (and not reducing) general well-being (from health, to education, to justice, to defense and mobility and so on) of the citizens. These two authors also studied the selection of model variables. Here, we will draw in particular: 1) the construction of a model of relative efficiency measurement once the production process in question (or in general a generic decision-making unit) can be modelled (a) as a network of two subprocesses, i.e., NDEA approach, and 2) the treatment of organisational policy preferences in these models by proposing our own solution. This paper does not provide any policy indications (which are specific to the work applied) and only presents our proposal on how to use the NDEA approach as a policy tool. From the managerial point of view, we also know that the decisions affect the variables of a model and concern some questions as follows: 1) in which direction the decisions on the model variables must be taken to improve organisational performances (reduction or increase)? 2) are the decisions in line with the objectives that managers must and/or want to pursue? (in our case, how the pursuing of objectives will coincide with the decision to leave the intermediate variable of the NDEA model unchanged and instead reduce the others); 3) which objectives are currently of interest to managers?; 4) which model variables are affected in the policy decision making; 5) how to set up a decision making process? (we will mention the use of inferential statistical approach); and 6) to what extent the factors external to the production process of goods and services influence their performance? The paper is structured as follows. In section 2, we describe our proposal. In section 3, we offer an application of the decision-making process and the analysis of external factors to a simple case, and in section 4 , we finally present the discussion and the conclusions.

\section{Method}

\subsection{An NDEA Relational Model for a Two Stages Production Process}

In this section we show our proposal. We show how to build a NDEA model for a production process with serie structure as those in Figure 1. Following ( (Castelli, Pesenti, \& Ukovich, 2010), (Castelli \& Pesenti, 2014), (Castelli, Pesenti, \& Ukovicha, 2001)) we build a multiplicative input oriented relational (with two relational variables, $z_{1}$ and $z_{2}$ in the Figure 1) NDEA model (Kao, 2009(a))with shared variables $\left(x_{2}\right.$ and $x_{3}$ in Figure 1) and one exogenous variables $\left(e_{1}\right)$ (see Note 5). NDEA relational model in (Kao, 2009(a)) use the same weights for all variables in the NDEA model. This allows them to apply a multiplicative decomposition formula to calculate sub process efficiency (Kao, 2009(a)). Here, we do not treat efficiency 's decomposition but we concentrate on the whole NDEA model (see Note 6) Once modelled a production process as those in Figure 1 a NDEA model must be designed to measure its relative performance. However, before solving the NDEA model in question, we will adopt the suggested linearization proposed in to build our linearized multiplication NDEA (see Note 7) model like the one in (Model 1) with input orientation measurement and under the assumption of constant scale returns (CRS) (see Note $8)$.

$$
\begin{gathered}
\max \sum_{r=1}^{S} u_{r} Y_{r o} \\
\text { s.t. } \sum_{i=1}^{m} v_{i} X_{i o}=1 \\
\sum_{r=1}^{s} u_{r} Y_{r k}-\sum_{i=1}^{m} v_{i} X_{i k} \leq 0 \\
\sum_{h=1}^{q} w_{h 1 k} Z_{h 1 k}-\sum_{i=1}^{p} v_{i k} X_{i 1 k}-\sum_{i=1}^{v} \alpha v_{i k} X_{i 1 k}^{S} \leq 0 \\
\sum_{r=1}^{s} u_{r} Y_{r k 2}-\sum_{h=1}^{t=q} w_{h k 2} Z_{h 2 k}-\sum_{j=1}^{u} \dot{w}_{J} N_{j 2}-\sum_{i=1}^{v}(1-\alpha) v_{i k} X_{i 2 k}^{S} \leq 0
\end{gathered}
$$

In (1), $N$ is the vector of exogenous variables for the second sub-process $\left(N \in R^{j} \operatorname{con} j=1\right)\left(e_{1}\right.$ in Figure 1$), \mathrm{Z}$ is the vector of intermediate variables $\left(z_{1}\right.$ and $z_{2}$ in Figure 1$), X^{S}$ is the vector of variables shared by sub-processes $X^{s} \in R^{i}(i=2)$ ( $x_{1}$ e $x_{2}$ in Figure 1) according to proportion $\alpha, \mathrm{Y}$ is system output vector $\left(y \in R^{r} \operatorname{con} r=1\right), \mathrm{X}$ is system input vector $\left(X \in R^{i}\right.$ con $\left.i=3\right)$. So, the variables $z_{1}$ and $z_{2}$ are the outputs of the first sub-process $\left(z \in R^{h} \operatorname{con} h=2\right)$ (the third constraint) and at the same time are the inputs of the second sub-process. The relational nature of the NDEA model in (1) is due to the fact that the same variables including and especially intermediate variables receive the same weights (w) (Kao, 2009(a)). Pedices 1 and 2 attached to variables indicate first and second sub-process. In the following sections we will present our proposal on how to use the NDEA approach as a policy tool by treating policy preferences on organizational goals as a "discretionary/non-discretionary" mix of variables within the model itself. As we will see below, in our proposal the 
choice of variables of the NDEA model to be treated as non-discretionary is crucial to treat organizational policy preferences. Our proposal provides that the NDEA model always makes at least one non-discretionary variable within it that is an intermediate variable or some of them, or that the exogenous variables are non-discretionary, or that some of them are non-discretionary, or other variables. In other words, our proposal characterizes the use of an NDEA model as a policy tool by defining the mix of discretionary-non-discretionary variables inside it. It is clear from now on that in this setting there is no trade-off between competing targets to define any pursuit priorities. The question is therefore asked differently than as discussed in. The output version of the (Model 1) can be written as follows:

$$
\begin{gathered}
\min \sum_{i=1}^{m} v_{i} X_{r o} \\
\text { s.t. } \sum_{r=1}^{s} u_{r} Y_{r o}=1 \\
-\sum_{\mathrm{r}=1}^{\mathrm{s}} \mathrm{u}_{\mathrm{r}} Y_{\mathrm{rk}}+\sum_{\mathrm{i}=1}^{\mathrm{m}} \mathrm{v}_{\mathrm{i}} X_{\mathrm{ik}} \geq 0 \\
-\sum_{h=1}^{q} w_{h 1 k} Z_{h 1 k}+\sum_{i=1}^{p} v_{i k} X_{i 1 k}+\sum_{i=1}^{v} \alpha v_{i k} X_{i 1 k}^{S} \quad \geq 0 \\
-\sum_{r=1}^{s} u_{r} Y_{r k 2}+\sum_{h=1}^{t=q} w_{h k 2} Z_{h 2 k}+\sum_{j=1}^{u} \dot{w}_{j} N_{j 2}+\sum_{i=1}^{v}(1-\alpha) v_{i k} X_{i 2 k}^{S} \quad \geq 0
\end{gathered}
$$

(Model 1 A)

The (Model $1 \mathrm{~A}$ ) aims to improve technical efficiency by not reducing organizational resources to the same amount of goods and services produced but on the contrary, with equal organizational resources engaged in production processes indicating how many goods and services in addition, they can be produced.

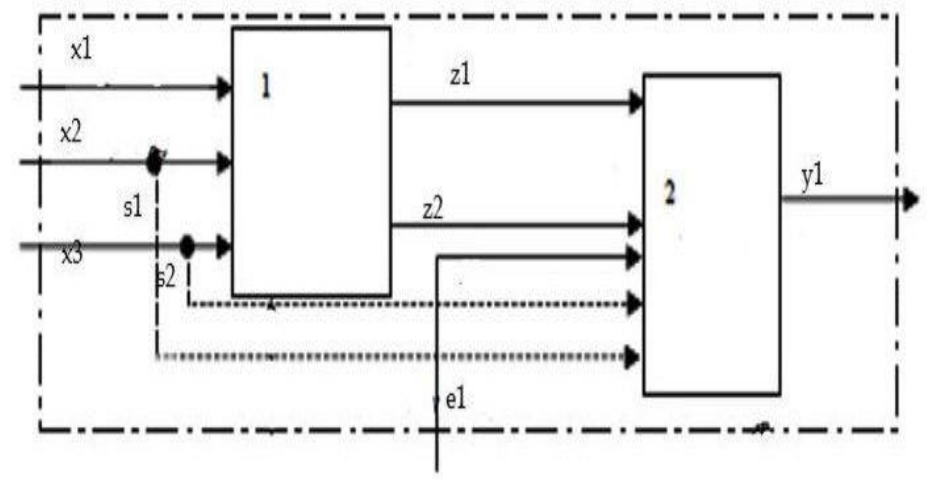

Figure 1. Two stage production process

\subsection{Treat Policy Preferences Within a NDEA Model: Assumptions on Variables}

In this example, managerial preferences relate to the pursuit of two distinct organizational objectives that are translated into a mix of discretionary/non-discretionary variables within an NDEA model such as the one indicated in (Model 2). As stated in (Smith \& Street, 2005) policy preferences in a DEA model are treated in terms of trade-off between competing and resolved targets by calculating on the data the excellent weights of each individual component of the outputs vector inserted into the DEA model and representing the product objective variables (i.e. the objectives to be pursued (see Note 9) and the weight variables. Here our proposal is to translate policy preferences on objectives into a mix of discretionary variables vs. non-discretionary variables in an NDEA model without raising the question of possible trade-off among them. The variables on which non-discretionary assumptions are placed is crucial for two reasons: 1) the variable(s) according to the sector considered and according to the objectives of researchers and managers must be judged as policy variables; 2) the assumption of non-discretionary assumptions must reflect in the preference system of managers/researchers/policy makers the pursuit of at least one objective. Therefore, in order to accommodate the preferences of policy on the organizational 
objectives in an NDEA model like the one in (1) we will resolve an NDEA model like the one below (Model 2)

$$
\begin{gathered}
\max \sum_{r=1}^{s} u_{r} Y_{r o}-\sum_{z=1}^{d} \widetilde{w}_{z} Z_{z o 2}^{N D} \\
\text { s.t. } \sum_{i=1}^{m} v_{i} X_{i o}=1 \\
\sum_{r=1}^{S} u_{r} Y_{r k}-\sum_{i=1}^{m} v_{i} X_{i k} \leq 0 \\
\left(\sum_{p=1}^{t} w_{h 1 k} Z_{h i k}^{D}+\sum_{p=1}^{T} \widetilde{w}_{h 1 k} Z_{h i k}^{N D}\right)-\sum_{i=1}^{p} v_{i k} X_{i 1 k}-\sum_{i=1}^{v} \alpha X_{i 1 k}^{S} \leq 0 \\
\sum_{r=1}^{S 1} u_{r} Y_{r k 2}-\left(\sum_{p=1}^{t} w_{h 2 k} Z_{p 2 k}^{D}+\sum_{z=1}^{d} \widetilde{w}_{h 2 k} Z_{z 2 k}^{N D}+\sum_{j=1}^{u} \dot{w}_{J} N_{j 2}+\sum_{i=1}^{v}(1-\alpha) X_{i 2 k}^{S}\right) \leq 0 \\
u, w, v, \widetilde{w}, \dot{w} \geq 0
\end{gathered}
$$

Where:

$Y_{r k}=$ outputs system ( $\mathrm{k}=\mathrm{o}$ is unit under evaluation)

$Z_{z k 2}^{N D}=$ not discretional relational variables

$X_{i k}=$ inputs system ( including exogenous variables $(\mathrm{N})$ )

$Z_{h 1 k}=$ output first sub process.

$X_{i 1 k}=$ inputs first sub process

$Y_{r k 2}=$ inputs of second sub process

$Z_{p 2}^{D}=$ discretional relazionale variables

$N_{J 2}=$ exogenous variables of second sub process

$\mathrm{k}=$ number of observation

$\mathrm{u}, \mathrm{v}, \mathrm{w}, \widetilde{w}, \dot{w}=$ weights variables

The (Model 2) is the same as the one in (Model 1) with the difference that in the (Model 2) we are assuming the non-discretionary nature of some relational variables. ( $\mathrm{Z}$ vs $Z^{N D}$ ) (Cooper, Seiford, \& Tone, 2007) (obviously this assumption can affect any other variable of the model) in order to replicate in the NDEA model a mix of discretionary vs. non-discretionary variables. As in the (Model 1), the first constraint is the normalization constraint introduced by (Charnes \& Cooper, 1962), the second is the system constraint, the third is the constraint of the first sub-process and finally, the fourth is the constraint of the second sub-process where $Y_{r k 2}=Y_{r k}$ (in other words in this model the outputs of the process are the outputs of the second sub-process, see Figure 1). The vector of relational variables $\mathrm{Z}$ is partitioned into two components $\mathrm{Z}=\left[Z^{D}, Z^{N D}\right]$, where $Z^{D}$ is the $Z$ ' sub-vector of discretionary relational variables while $Z^{N D}$ the $Z$ 'sub-vector of "non-discretionary" relational variables. $X^{S}$ is the vector of resources shared between sub-processes 1 and 2 in proportions $\alpha e(1-\alpha)$. In the NDEA (Model 2) we are assuming that the policy preferences set by organizational managers establish only one additional goal to be pursued in addition to the natural efficiency goal inherent in the model, which as we will see in the application will correspond to a welfare goal (as this will be clearer in the application example). The use of the NDEA model as a policy tool is substantiated as described above, that is, to define within it which variable(s) is (are) that of alternative policy to those of efficiency and, as happens here, if appropriate assume it as non-discretionary. Anticipating 
somethings on the application that will follow, we know that in the area of health services a policy goal is to maintain or otherwise not reduce access to health services. It will then be up to the researcher to identify this policy variable and insert it into the NDEA model in order to bend it to a policy variable and assume it non-discretionary or discretionary as appropriate. Here we omit to return the version to the output of the (Model 2) as the application as an example will only interest the (Model 1). The interpretation of the results for the Model 2 in its output version is the one provided to the model $(1 \mathrm{~A})$ with the necessary interpretive measures in the case of output models related, as you are talking here, to the use of these models as policy models.

\section{Data and Application: The Public Health Service Example}

In this section we will offer an application of the (Model 2) presented above to the public hospital care services sector starting from the NDEA model proposed in (Pinto, 2016) in which the process of treating acute hospital care is modeled as a two-stage process. Obviously also in as here the model is a stylization and simplification of the real production process of acute hospital care (see Note 10). Other similar applications of NDEA models can be found for example in(Seiford \& Zhu, 1999). Hospitals generally offer services that can be classified differently, for example it is possible to distinguish between acute and rehabilitation services (see Note 11) or distinguish between surgical services and medical services and so on. This means that the population can access the various hospital services both for treatment and for prevention or control, etc., etc. In general, therefore, people have access to hospital services to improve their health or restore the health damaged by the disease. This means that improving the health status of the population or restoring the health damaged by the disease is an important objective of general and hospital health policy and requires the widest possible access to hospital services (and health services in general). Maximizing or not reducing access to public (and also private) health services in general and hospital services is a health welfare objective. For hospital managers and public health policy makers, maintaining access to hospital health services (in particular public health services) while providing the medical and surgical care necessary to meet the health needs of the population in a context of public scarces resources or in any case reduced resources is therefore very important. In the following subsections we will present our dataset (3.1), the application of the NDEA model (2) developed here (3.2) and finally we will discuss the effects of the introduction of policy preferences on the measurement of efficiency by developing a simple statistical decision-making process (3.3.), finally another subsection is dedicated to the analysis of external factors.

\subsection{Data Set}

To solve the (Model 1) and (Model 2) we will use hospital input and output data published by the Italian Ministry of Health extracted from the "National Health Service Database" files (see Note 12)" (Health \& Ministry, 2016). Our data set contains $\mathrm{N}=554$ observations and 37 variables for the year 2013 with seven different types of public hospitals: 30 Hospitals Trust, 27 Hospitals integrated with the National Health System and the University, 389 Hospitals directly managed by the Local Health Authorities, 3 Research Institutes, 60 Scientific Research and Treatment Institutes (IRCSS), 28 equivalent public facilities, 17 qualified facilities managed by the Local Health Units. The structures are distributed over 19 Regions and two Autonomous Provinces. After aggregating the variables (e.g. the nurses variable is the aggregation of the variables of care operators of category I and II), the final data set will contain the variables described in Table 1 below.

Table 1. The hospital dataset variables description

\begin{tabular}{ll}
\hline Variabili & Description \\
\hline Doctors & Number of doctors e odontoiatric \\
\hline Nurses & Numberof I and II category assistant \\
\hline Rehabilitative staff & Number of rehabilitative staff di personale di riabilitazione \\
\hline Health-technical staff & Number of health-technical staff di personale tecnico medico \\
\hline Research staff & Number of teaching \\
\hline Administrative staffi & Administrative staff amministrativo (director, collaborators, auxiliary) \\
\hline Other health staff & Sum of health personnel (psicologist, chemistry, biology, farmacist) \\
\hline
\end{tabular}




\begin{tabular}{ll}
\hline Other non health staff & Sum of not health staff (layers, vigilantes, architect, and so on) \\
\hline Ordinary beds & Number of ordinary beds \\
\hline Day hospital beds & Numberof day hospital beds \\
\hline Day surgery beds & Number of day surgery beds \\
\hline Ordinary discharges & Number of ordinary discharges dimissioni ordinarie \\
\hline Day hospital discharges & Number of day hospital discharges \\
\hline Surgical discharges & Number of surgical discharges \\
\hline Days on hospital & Number of day on hospitals \\
\hline Pre-operation days on hospital & Number of pre operation day on hospitals \\
\hline Average stay on hospital & Average day on hospital \\
\hline Surgical interventions & Number of surgical interventions \\
\hline Case Mix Index & Case mix index \\
\hline
\end{tabular}

The descriptive statistics of variables indicated in Table 1 refer to the year 2013 with 554 observations and are in Table 2.

Table 2. Descriptive statistics of variables (Year: 2013; $\mathrm{N}=554$ )

\begin{tabular}{|c|c|c|c|c|c|c|c|}
\hline \multirow[b]{2}{*}{ Variables } & \multicolumn{7}{|c|}{ Descriptive statistics } \\
\hline & Mean & s.d. & Median & Min & Max & I Quartile & $\begin{array}{l}\text { IV } \\
\text { Quartile }\end{array}$ \\
\hline Doctors & 184,1986 & 192,7134 & 114,5 & 0 & 1597 & 52,25 & 264,75 \\
\hline Nurses & 435,7527 & 459,5049 & 268 & 0 & 3650 & 117,25 & 636,25 \\
\hline Rehabilitative staff & 24,02166 & 32,15491 & 11 & 0 & 210 & 3 & 33,75 \\
\hline Health-technical staff & 65,59386 & 77,76661 & 36 & 0 & 732 & 16 & 91,75 \\
\hline Research staff & 1,301444 & 3,149287 & 0 & 0 & 27 & 0 & 1 \\
\hline Administrative staffi & 70,24007 & 112,3921 & 26 & 0 & 1328 & 11 & 78,5 \\
\hline Other health staff & 15,11913 & 21,96389 & 8 & 0 & 194 & 3 & 18 \\
\hline Other non health staff & 181,0235 & 229,0032 & 96 & 0 & 2139 & 45 & 229,25 \\
\hline Ordinary beds & 284,2816 & 277,3422 & 183 & 6 & 1931 & 94,25 & 396,75 \\
\hline Day hospital beds & 20,74729 & 29,04585 & 11 & 0 & 236 & 4 & 25 \\
\hline Day surgery beds & 8,962094 & 12,61649 & 5 & 0 & 112 & 0 & 13 \\
\hline Ordinary discharges & 10376,67 & 10233,83 & 6806 & 0 & 61778 & 2798,5 & 14543,5 \\
\hline Day hospital discharges & 1284,018 & 1554,526 & 769 & 0 & 10469 & 232,25 & 1730,25 \\
\hline Surgical discharges & 4329,59 & 4981,848 & 2547 & 0 & 35737 & 1020 & 5858,75 \\
\hline Days on hospital & 81061,94 & 80695,38 & 50268,5 & 0 & 521573 & 24452,5 & 115754,5 \\
\hline Pre-operation days on hospital & 16219,48 & 20076,07 & 8350,5 & 0 & 133690 & 3371,5 & 21592,25 \\
\hline Average stay on hospital & 11,58179 & 11,76222 & 8,710509 & 0 & 102,6 & 7,01666 & 10,69954 \\
\hline Surgical interventions & 13529,62 & 16684,63 & 8126 & 0 & 135697 & 3201 & 18456 \\
\hline Case Mix Index & 0,943744 & 0,150521 & 0,94 & 0 & 1,896667 & 0,87361 & 1,013439 \\
\hline
\end{tabular}

In our analysis sample, as we can read in Table 1, during 2013 on average one hospital in the sample employed about 
184 doctors, 435 nurses, 24 units of rehabilitation personnel, 66 units of technical-healthcare personnel, 1 teacher, 70 units of administrative personnel, 15 units of other medical staff and 181 units of non-medical personnel. The hospital activity, again on average, required the use of 284 ordinary beds, 20 day hospital beds and 9 day surgery beds to produce an average of 10377 ordinary discharges, 1284 day hospital discharges, 4330 surgical discharges, 81062 days of ordinary hospitalization, 13530 surgical interventions with 16219 days of pre-operative hospitalization. On average, one hospital in our sample treated a hospital case mix index with an average complexity equal to 0.9437 (below the standard of 1), while on average the maximum average complexity of the case mix index was $1.9 .25 \%$ of the hospitals in the sample (about 139 out of 554) employed less than 53 doctors, 117 nurses, 3 units of rehabilitation personnel, 16 units of technical-healthcare personnel, 0 teachers, 11 units of administrative personnel, 3 units of other medical staff and 45 units of non-medical personnel, using about 94 ordinary beds, 4 beds in day hospital and 0 beds in day surgery to produce about 2798 ordinary discharges, 10469 day hospital discharges, 35737 surgeries, 521573 days of hospitalization, 135697 surgeries with 133690 days of pre-operative hospitalization. Still $25 \%$ of the hospitals in the sample treated cases with an average complexity of $0.837 .50 \%$ of the hospitals, i.e. the median hospital, employed 114 doctors, 268 nurses, 11 units of rehabilitation personnel, 36 units of medical-health personnel, 0 teachers, 26 units of administrative personnel, 8 units of other medical personnel and 96 units of non-medical personnel using approximately 183 ordinary beds, 11 beds in day hospital and 5 beds in day surgery to produce approximately 6806 ordinary discharges, 769 discharges in day hospital, 2547 surgeries, 50268 days of hospitalization, 16685 surgeries with 8350 days of pre-operative hospitalization and a 0 . 94. Our sample contains about 139 small hospitals (beds $<120$ ) and on average these small hospitals treated a case history with a Case Mix Index (CMI) (see Note 13) of 0.87. Although the objective of the paper is not the classification and evaluation of scale returns of hospitals, the information on the number of small hospitals just provided may be useful to get an idea of how many small hospitals are involved in our NDEA programme.

\subsection{Public Sector Application: The Case of Hospitals}

In this section we will present the results of our application. Figure 2 presents a simple and stylized production process for acute care hospital services developed in to which we will apply our NDEA (Model 2).By adapting the NDEA (Model 2) to the process shown in Figure 2 we will have the following NDEA (Model 3):

$$
\begin{aligned}
& \max \left(u_{1} \text { Dimissioni totali } i_{i o}\right)-\widetilde{w}_{1} \text { Interventi chirurgici } i_{i o}^{N D} \\
& \text { s.t. } \quad v_{1 i} \text { Medici }_{i}+v_{2 i} \text { Posti letto totali } i_{i}+v_{3 i} \text { personale tecnico }- \text { sanitario }_{i}+v_{4 i} \text { Infermier }_{i}=1 \\
& u_{1} \text { Discharges }_{i}-\left(v_{1 i} \text { Physicians }_{i}+v_{2 i} \text { Beds }_{i}+v_{3 i} \text { Med }- \text { Tech }_{i}+v_{4 i} \text { Nurses }_{i}\right) \leq 0 \quad \text { (Model 3) } \\
& \left(w_{2 i} \text { Days on hospitals }_{i}+\widetilde{w}_{1 i} \text { Surgical interventions }_{i}^{N D}\right)-\left(v_{1 i} \text { Physicians }_{i}+v_{2 i} \alpha \text { Beds }_{i}+v_{3 i} \beta \text { Med }- \text { tech }_{i}\right) \leq 0 \\
& u_{1 i} \text { Discharges }_{i}-\left(\widetilde{w}_{1 i} \text { Surgical interventions }_{i}^{N D}+w_{2 i} \text { Days on hospitals }_{i}+v_{2 i}(1-\alpha) \text { Beds }_{i}+v_{3 i}(1-\beta) \text { Med }_{\text {tech }_{i}}+\dot{w}_{1 i} \text { Nurses }_{i}\right) \leq 0 \\
& \mathrm{u}, \mathrm{v}, \mathrm{w}, \widetilde{\mathrm{w}}, \dot{\mathrm{w}}>0
\end{aligned}
$$

As can be seen in the (Model 3) the non-discretionary variable included in the objective function of the NDEA program is an organizational policy variable that concerns the welfare objective and is the intermediate variable of surgical interventions whose weight (w). In the health services sector, in fact, access to hospital surgical treatments is one of the crucial elements of organizational policy as the surgical act is the act par excellence designed to restore the damaged health of individuals. Maintaining unchanged the possibility of access to hospital surgical services by not reducing the amount of surgical services that can be provided in a context of limited hospital resources is therefore an objective of hospital health policy that hospital managers cannot neglect. In short, the system of corporate objectives that we are representing here for a hospital is composed of two objectives, one of efficiency (optimize the use of resources) and one of welfare (do nor reduce the access to surgical services). The pursuit of these two objectives is translated here into an NDEA model in the form of a mix of discretionary and non-discretionary variables as it emerges from the (Model 3). In particular, the (relative) efficiency objective is pursued through a more efficient use of the resources used both by the entire production process and its sub-processes. It is measured with an input oriented relational NDEA model by treating the variables concerned by efficiency improvement as discretionary variables (e.g. for beds, see Table 2a). The welfare objective of not reducing access to hospital surgical services is instead pursued by treating the relational variable "surgical interventions" as non-discretionary (see Table 2s). Thus, given these specifications on NDEA model variables, the latter is used as an organizational policy tool. The mix of discretional/non-discretional variables adopted for this example is summarized in Table 2a. 


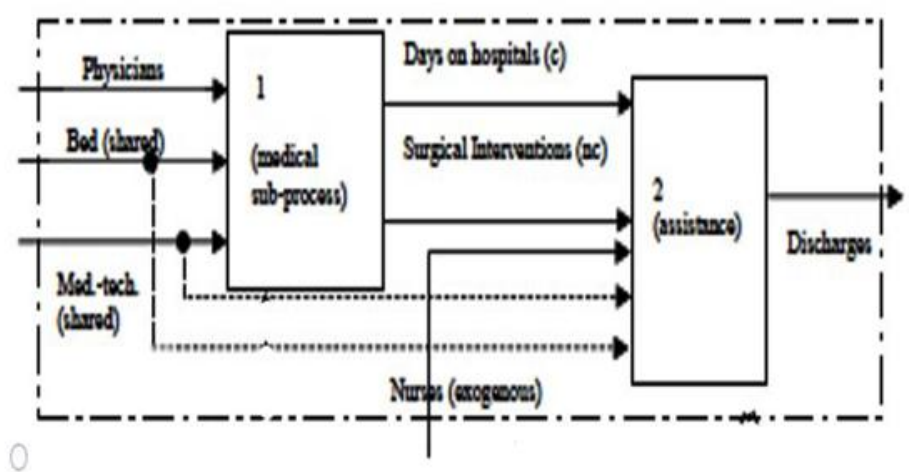

Prodaction process of the hospital actute care services

Figure 2. Adaptation of the graphic model in Figure 1 to the hospital case

Tablea 2a. Discretional/not-discretional mix variables

\begin{tabular}{ll}
\hline Mix di variabili & \\
\hline Discretional & Not discretional \\
\hline -Doctors & -Surgical interventions \\
\hline -Nurse & \\
\hline -Tech-health staff & \\
\hline -Beds & \\
\hline
\end{tabular}

In Table 3, we report instead the descriptive statistics of relative relational efficiency measurements under the assumptions of constant and variable scale returns for NDEA models in which the "discretionary/non-discretionary" variable mix (Model 3) and for models without the mix (Model 3 without not discretional assumption) is inserted. This double measurement will be used to test the effect of the adoption of the whole mix on the mere measurement of the efficiency performed with the NDEA1 model. It is at the same time the way to delineate the boundary between an NDEA model not used as a multi-objective policy tool (NDEA 1 model) and an NDEA model used as a multi-objective policy tool (NDEA2 model).

Table 3. The descriptive statistics of NDEA model efficiency scores. Year 2013. N=554.

\begin{tabular}{llllll}
\hline Model & Descriptive statistics & & & \\
\hline \multicolumn{7}{l}{ CRS } \\
Mean & s. d. & Median & I Q & IIIQ \\
\hline NDEA (1)(Model 3 less N.D.) & 0.56778 & 0,17720 & 0,55497 & 0,47635 & 0,65073 \\
\hline NDEA (2)(Model 3) & 0,55637 & 0,17778 & 0,54017 & 0,46509 & 0,63751 \\
\hline VRS & & & & \\
\hline NDEA (1) & 0,557502 & 0,176736 & 0,540171 & 0,465094 & 0,637513 \\
\hline NDEA (2) & 0,63320 & 0,209007 & 0,621692 & 0,500256 & 0,771302 \\
\hline $\begin{array}{l}\text { Legend: NDEA(1) is the relational model developed in (1) where all the variables are discretionary and } \\
\text { there are two shared variables (beds and health technicians), no common variable and the second } \\
\text { sub-process has an exogenous variable; } \text { NDEA(2) has a non-discretionary relational variable (surgeries) } \\
\text { with two shared variables (beds and health technicians). }\end{array}$ \\
\hline
\end{tabular}


We can already see that in the case of constant scale returns the introduction of the "discretionary/non-discretionary" mix on average does not generate substantial differences in relative performance measurement (see Note 14). Opposite evidence is found in the case of variable scale returns. In particular, the introduction of the mix in the NDEA 2 model generates, on average, greater efficiency if it is assumed that both the entire process and its sub-processes operate with variable scale returns and therefore efficiency improvements can also be achieved through scale adjustments. In other words, when we assume that the whole process of medical and surgical treatment of acute hospital care as well as its two sub-processes of actual care and assistance can also operate with increasing and decreasing scale returns as well as with constant scale returns, the pursuit of the two objectives has an impact on the measurement of the relative efficiency of the whole process (see Note 15), in other words, in this latter case (with the assumption of variable scale returns) the ability to pursue a different overall company performance is influenced by the possibility of scale adjustments, increasing its general relative performance on average. In order to argue that these differences are empirically significant and able to support any managerial decisions, we need to deepen the analysis and we will do it through the graphical comparison (Figures 3,4 and 5) of the functions of empirical cumulative distribution of relational efficiency scores and then we will set up a simple decision making process of a statistical nature. In the following subsection we will then show some graphs and the results of statistical tests underpinning the decision-making process.

3.2.1 Discussion of the Effects on the Efficiency Measurement of the Introduction of Policy's Preference: Our Example

In this subsection, we will discuss the consequences that the introduction of the mix of "discretionary/non-discretionary" assumptions on variables has on the measurement of relative relational performance. We will then set up a simple decision-making process based on statistical tests of hypotheses and the comparison of the functions of cumulative empirical distribution of relational efficiency scores. In particular, we will conduct tests and graphical comparisons between NDEA 1 (Model 3 without n.d. variables) and NDEA 2 (Model 3) models under the hypotheses of constant returns of scale and variable returns of scale (see Figure 3 and Table 5 and Figure 4 and Table 6, respectively). The comparison will also consider the measurements conducted using NDEA 2 (Mdel 3) model but under different scale assumptions (see Figure 5 and Table 7).
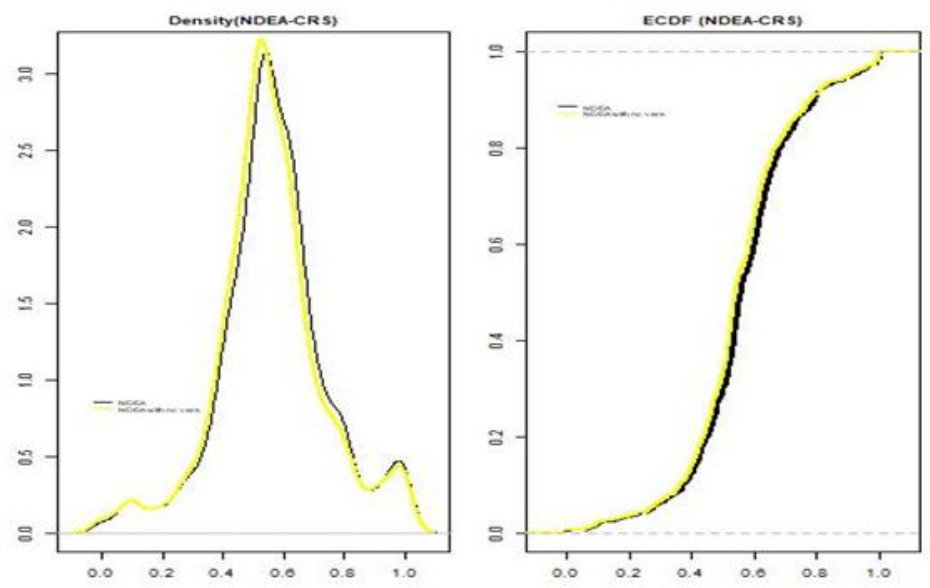

Figure 3. Density (sx) and empirical cumulative distribution function' efficiency scores under constant return to scale $(\mathrm{dx})$ 

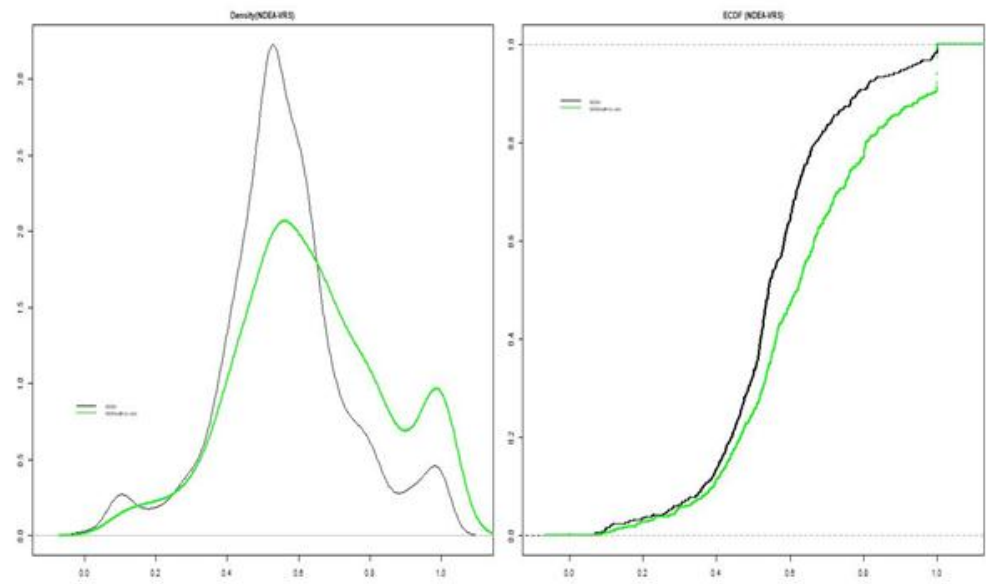

Figure 4. Density (sx) and empirical cumulative distribution function' efficiency scores under variables return to scale $(\mathrm{dx})$

Figure 3 depicts the comparison between the density function and the cumulative empirical distribution functions of the relative relational performance scores between NDEA 1 and NDEA 2 models under the assumption of constant returns to scale. With these assumptions, further improvements in organisational performance cannot be pursued through scale adjustments. Figure 4 instead considers the same functions for the same two models (NDEA 1 and NDEA 2) but under the assumption of variable returns of scale. In this latter case, general performance improvements can also be achieved through scale adjustments, also. According us, the differences between the two curves highlight the effects of introducing the "discretionary/non-discretionary" mix of variables on general performance measurement (in the first case, NDEA 1 measurement, the overall performance coincides with the measurement of the efficiency target, in the second, NDEA 2, with both targets). In other words, these differences signal the effects of introducing policy preferences on organisational objectives when the NDEA model is used as a policy tool with two objectives (Model 3) and when it is not (Model 3 without n.d. assumptions). The differences observed in these graphs confirm the differences in relational performances in the case of variable scale, as evident in Table 3 and Figure 4. To consider the effects of different returns of scale assumptions on the pursuit of the efficiency objective once the policy preferences have been entered on all the other objectives, we will compare the measurement with Model 3 under different hypotheses of returns of scale (constant return to scale, black line, and variables return to scale, cyan line) ( see Figure 5).Our interpretations of Figures 3 and 4 are as follows. 1) Figure 3 shows that $80 \%$ of the decision units of the sample pursuing both objectives ( yellow line model) record a performance of $<90 \%$ when it is assumed that all the decision-making units/production processes and its sub process operate in coincidence with the constant returns of scale (i.e., scale adjustments are not assumed). This is true alsowhen the system of the objectives for the DMU of the sample is made up solely of the efficiency objective. In fact, both models generate very similar empirical distributions of general performance scores. In other words, $80 \%$ of the units of our sample pursuing both efficiency and welfare objectives can improve their technical efficiency (pursuit the efficiency objective) without prejudice to the process of pursuing the second ( the welfare objective )2) Figure 4, which refers instead to the same sample of decision-making units but for which efficiency improvements are assumed to be pursued through scale adjustments, also, tells us instead that approximately $80 \%$ of the units in the sample that pursue a single objective ( black line) show a performance of less than $90 \%$ For the DMUs that pursue both objectives (green line in Figure 4), the percentage of units with performance $<70 \%$ involve $80 \%$ of the sample instead of $80 \%$ ( $10 \%$ less) (the green coloured line is below the black one in the Figure 4). This suggests that when efficiency gains can also be pursued through scale adjustments then, in our example, there is a trade-off between the pursuit of the both objectives (welfare objective and that of efficiency) with respect to the pursuit of the efficiency objective only. In other words, pursuing the second goal (welfare), along with that of efficiency when decision-making units can improve their performance even by adjusting the operating scale, reduces the units that can do so from $80 \%$ to $70 \%$. For us, this too is a trade-off. The comparison of these results with those of Figure 3 in which scale adjustments are not possible shows that it tends to disappear as can be seen in Figure 3 where the two curves overlap. This interpretation of Figure 4 is based on the evidence that the black curve is above the green one 
(Model 3 with two objectives). We are led to interpret this evidence in the sense that engaging organisational energies only to achieve the objective of efficiency also with scale adjustments is associated with better overall performance (one possible explanation is that the organization is focusing on one goal instead of two.). If we had be observed that the green coloured curve (system with the two objectives) was above the near instead of below in Figure 4, then we would have made the opposite interpretation. Figure 5 refers to the same model (Model 3), i.e., when the decision-making units of our sample are pursuing both objectives, but assumes once the returns of constant scale (black line) and then the returns of variable scale (cyan colour line). In trade-offs terms, it emerges not between the systems of objectives but among the improvements of performance through the adjustments of scale. In our opinion, we can then interpret it as follows: given the evident difference between the two curves in favour of the one under the hypothesis of constant returns of scale (the black line is above the cyan one), all the DMUs on the efficient frontier of the (cyan-coloured line) can firstly operate to obtain further improvements in relative relational efficiency through scale adjustments (see Note 16) (resolving the trade-off) and then pursue the other policy preferences of the managers defined here. In other words, if, for example, a process is entirely technically efficient and operates on the efficient frontier portion of the increasing scale returns (cyan line), then a scale adjustment in the sense of an increase in its size is necessary to reach the condition of constant scale returns (on the black line) (where no other scale adjustment is needed). This generates further efficiency improvements that do not conflict with the pursuit of the second welfare objective (at least in our sample). In summary, we say that, in our sample, the pursuit of the welfare objective by managers of public hospitals presents a trade-off with that of efficiency by reducing the percentage of observations with an efficiency score of $<70 \%$ (Figure 4), but it is facilitated by scale adjustments. In fact, as can be seen in Figure 5, if this adjustment occurs for all the units that need it, then it increases the efficient portion of the DMU. In our opinion, this result is strictly linked to the orientation of the measurement (at the input) and valid only for our sample. However, this result can also find an intuitive explanation, i.e., wanting to reduce resources (improve technical efficiency) would hinder the pursuit of the welfare objective (maintain access to hospital surgical services unaltered). This latter objective (as additional to that of efficiency) can be pursued, for example, if the operating scale is increased (for those units that are operating in the area of increasing returns to scale). Conversely, sometimes to keep this second objective (access to surgical services) unaltered, a scaling down of the scale is required if the process in question is currently operating in the area of decreasing returns to scale. Opposite but not specular considerations can be produced if the curves in Figure 5 under the hypothesis of returns of variable scale had been higher than those under the hypothesis of returns of constant scale. In other words, pursuing the welfare objective that would also require scaling adjustments by moving the units from the yield curve of variable scale to the yield curve of constant scale (further down) would have reduced technical efficiency and the sample percentage (bringing it to $80 \%$ ) with an efficiency score, for example $<80 \%$. These observations based only on graphs must find a more solid empirical basis before the managers opt for relative decisions (see Note 17). In statistics, a decision-making process can be set up using statistical tests on distributions. In this regard, we will set up a simple statistical decision-making process using the following statistical tests: Kolmogorov-Smirnov (KS) test, Wilcox (W) signed rank test, the Kruskal-Wallis (KW) test and the Mann-Whitney (MW) test. The proposed decision-making process is multidimensional with the following steps:

Decision rule: reject null hypothesis H_o if p-value is less or equal significance level of $(0.05)$ or if calculated value of the statistical test is greater calculated critical value of the statistics

Decision: reject (accept) H_o is p-value is < 0.05 (i.e. 0,004) $(>0.5)$ or reject (accept) H_Oif calculated value of the statistics is greater (less) than critical value.

Inference: depends at this point on the test used. For example in the case of the Kolmogorow-Sminorv (KS) test the null hypothesis H_o in the case of two samples is that the empirical distributions compared are the same or/and come from the same theoretical distribution. So in the case of this test in Table 5 we cannot reject H_0 that the two distributions are the same. Since the results in Table 5 refer to the comparison of empirical distributions of relative efficiency scores in the case of constant scale returns, we infer that the effects of the introduction of the "discretionary/non-discretionary" mix on the variables of our model (in particular the assumption of non-discretion on surgical interventions in combination with the assumption of discretion of all other model inputs) has no effect on the measurement when the NDEA model assumes constant scale returns, Therefore, managerial policy preferences have no effect on the measurement of the efficiency of our production process, assuming that it and its sub-processes all operate at constant scale returns. The discussion is completed below.

For example, suppose that managers/researchers have different preferences on two systems of different objectives, one of which is constituted by the objective of improving efficiency and one of improving (or in any case not 
worsening) a welfare objective while the other system of preferences always consist of the objective of improving efficiency and another of improving quality (see Note 18). For both systems of objectives, the managers/researchers could test whether pursuing the objectives in each of the systems of preferences conflicts with the scale adjustments or not. Therefore, the option for managers/researchers is to set up a decision-making process based on the statistical tests indicated above (or other useful purposes). In the case of the first example of preference system, the hypothesis to be tested could be whether pursuing the welfare objective conflicts with the scale adjustments (which we did in the application) or whether pursuing the welfare objective conflicts with that of technical efficiency. Another hypothesis could also be whether the proposed system allows scale adjustments without worsening the efficiency of the entire process and its sub-processes once the efficiency objective has been achieved as an additional objective included in each system of preference. Some of the hypotheses are those followed in the application. The statistical test results for our sample are reported in Tables 5,6 and 7. We statistically record that the need for scale adjustments (the comparison shown in Figure 5) is supported by the test results (see Table 7). Tables 5 and 6, on the other hand, refer to the hypotheses related to the effects of introducing the "discretionary/non-discretionary" mix on measuring efficiency.

Table 5. Test statistici: scores di efficienza sotto assunzione di ritorni di scala costanti (Year=2013; N=554)

\begin{tabular}{lll}
\hline Tests & & NDEA (1) vs NDEA (2) \\
\hline Kolmogorow-Sminorv & p-value & 0.14752 \\
\hline Mann-Whitney & Statistic & 0.06859 \\
\hline & p-value & 0.13676 \\
\hline Kruskal-Wallis & Statistic & 161383 \\
\hline Wilcox signed rank test & p-value & 0.47595 \\
\hline & Statistic & 549.3313 \\
\hline & p-value & 0.13676 \\
\hline
\end{tabular}

In Table 5, we test the hypothesis that the two distributions of performance measurements under the hypothesis of constant returns to scale for the decision-making units that once pursued the only efficiency objective (NDEA model 1) and the other instead pursue both objectives (NDEA 2 models) are the same or at least that the difference between them is not statistically significantly evident. Table 6 shows the results for the same test but when applied to the distributions of the measurements conducted with NDEA models under the hypothesis of variable returns of scale. In Table 7, we report the same comparisons but the distributions of performance measurements with the same model (NDEA 2) and under two different hypotheses on the returns to scale. With this last test, we want to test the hypothesis that scale adjustments do not conflict with the complete system of objectives. The results of the statistical tests reported in Table 5 suggest that we cannot reject the null hypothesis (H_0) (4 times out of 4), i.e., at the 5\% significance level, the two distributions of the efficiency scores for NDEA 2 and NDEA 1 models. This is because, for example, the p-value of the KS test is 0.147, which is greater than the significance level of 5\% (0.05). From this, we infer that the introduction of the assumption of non-discretion on our relational variable "surgical interventions" had no effect on the measurement of relative relational efficiency of our production process in the analysed sample under the assumption that they operate in the regime of returns of scale constant. In other words, in this case, the decision to pursue the welfare objective does not hinder the possibility of obtaining a better economic performance (in particular, relational technical efficiency) for our sample. In other words, pursuing both objectives for the units of our sample does not worsen the overall performance (see Note 19) of the process. This evidence is also supported by other tests such as the KW, W, and MW tests. If we assume variable scale conditions (i.e., both ascending and descending as well as constant), the results of the statistical tests are reported in Table 6. 
Table 6. Test statistici: scores di efficienza sotto assunzione di ritorni di scala costanti (Year=2013; N=554)

\begin{tabular}{lll}
\hline Tests & \multicolumn{2}{c}{$\begin{array}{l}\text { NDEA (1) vs NDEA } \\
(2)\end{array}$} \\
\hline Kolmogorow-Sminorv & p-value & $2.430 \mathrm{E}^{\wedge}-11$ \\
\hline Mann-Whitney & Statistic & 0.21299 \\
\hline & p-value & $1.12 \mathrm{e}^{\wedge}-10$ \\
\hline Kruskal-Wallis & Statistic & 119105,5 \\
\hline & p-value & 0.181396 \\
\hline Wilcox sum rank test & Statistic & 531,7306 \\
\hline & p-value & $1.12 \mathrm{E}^{\wedge}-10$ \\
\hline & Statistic & 119105,5
\end{tabular}

As can be read in Table 6, assuming the hypothesis of variable returns of scale, we cannot accept the null hypothesis that the two distributions are the same or that they come from the same distribution. With respect to the test, we can say that the positive difference in favour of the black curve (measurements with the NDEA 1 model) is statistically significant. Therefore, on average, the best general performances for our sample, in the presence of the possibility of scale adjustments, occur when the decision-making units adopt a single objective system (i.e., only that of efficiency). In Table 7, which refers to the comparison between the measurements obtained from the NDEA2 model itself under the assumptions of returns of constant and variable scale, the differences between the distributions of the efficiency scores are statistically significant (we cannot accept Ho). Thus, we can offer the following interpretation: to effectively pursue the complete system of objectives, it is preferable to operate with constant returns of scale, or in other words, the weight of both objectives for the units of our sample is carried out after the scale adjustments. Therefore, further policy decisions can be set on these other two tables. For example, for all the tests in Table 7, we cannot reject the relative null hypotheses; therefore, the scale effects are statistically significant and the relative policy decision would then be to proceed to scale adjustments to facilitate the more effective pursuit of the entire system of preferences.

Table 7 Statistical tests: comparison of distributions with constant and variable scale returns (Year=2013; N=554)

\begin{tabular}{lll}
\hline Tests & & CRS-NDEA (2) vs VRS-NDEA (2) \\
\hline Kolmogorow-Sminorv & p-value & $2,43 \mathrm{E}-11$ \\
\hline Mann-Whitney & statistic & 0,212996 \\
\hline & p-value & $8,98 \mathrm{E}-11$ \\
\hline Kruskal-Wallis & statistic & 187986,5 \\
\hline Wilcox sum rank test & p-value & 0,470534 \\
\hline & statistic & 549,7828 \\
\hline & p-value & $8,98 \mathrm{E}-11$ \\
\hline & statistic & 118929,5 \\
\hline
\end{tabular}



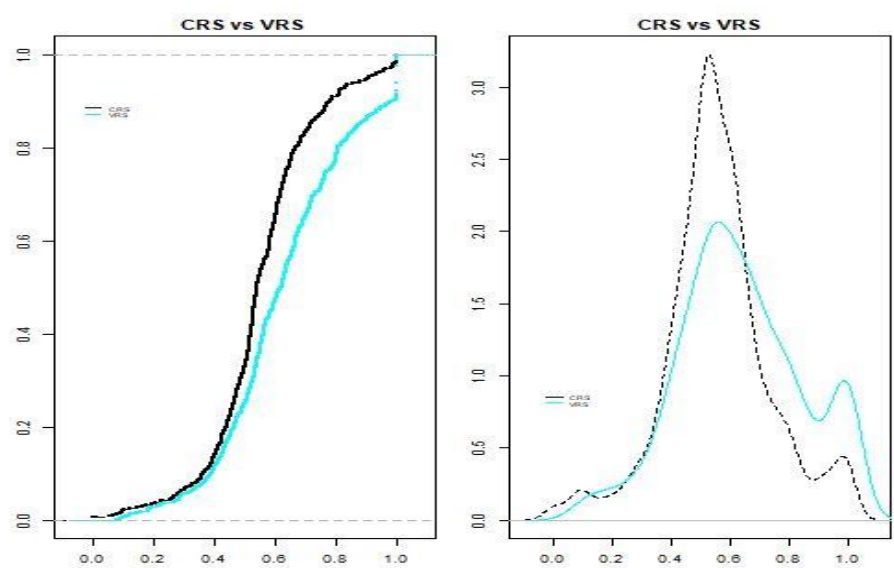

Figure 5. Density(sx) and empirical cumulative distribution function' efficiency scores (dx) NDEA (2) model under constant and variables return to scales
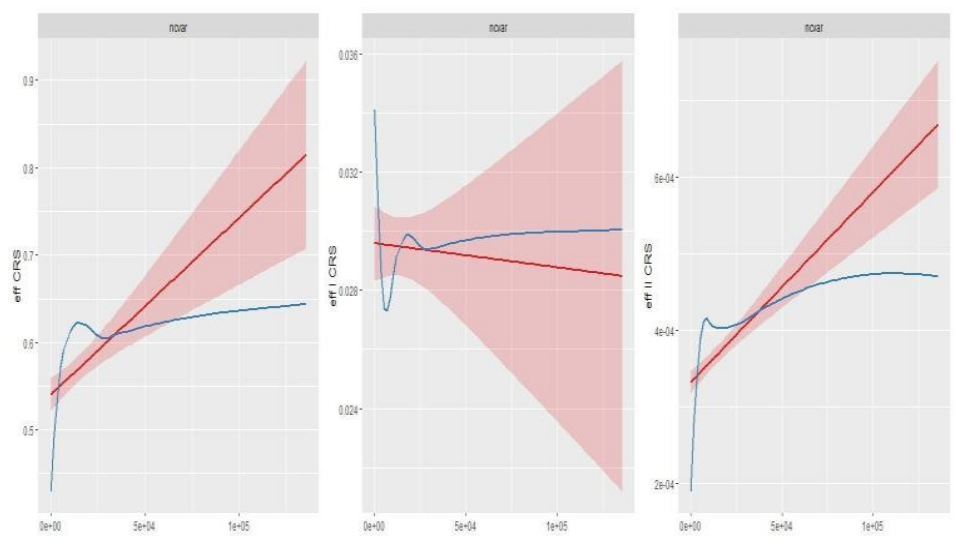

Figure 6. Relation of the non-discretionary assumed variable to the efficiency of the system and its sub-processes in the case of the NDEA model with all the relational variables assumed discretionary in the case of scale returns assumption
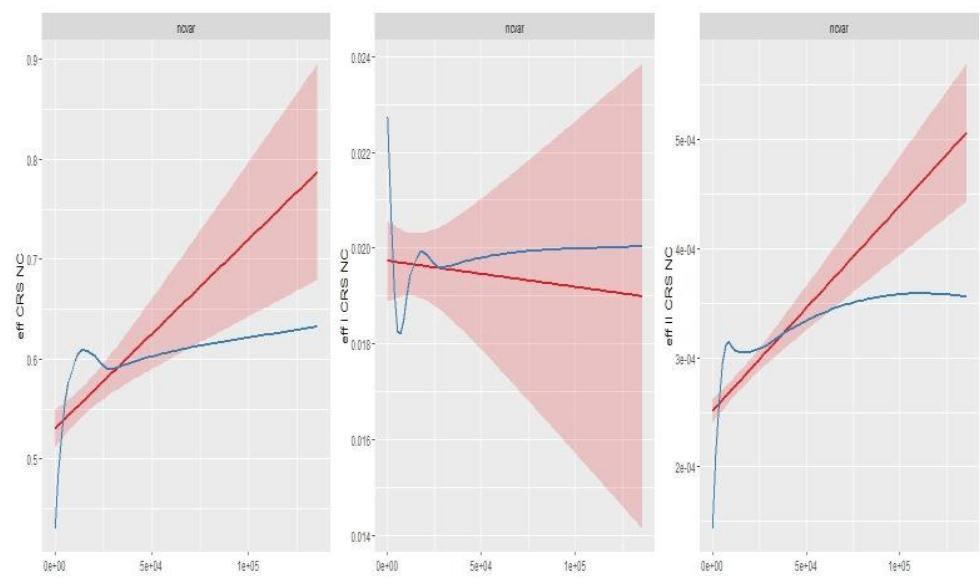

Figure 7. Relation of the non-discretionary assumed variable to the efficiency of the system and its sub-processes in the case of the NDEA model where a relational variable is assumed to be non-discretionary in the case of constant return to scale 

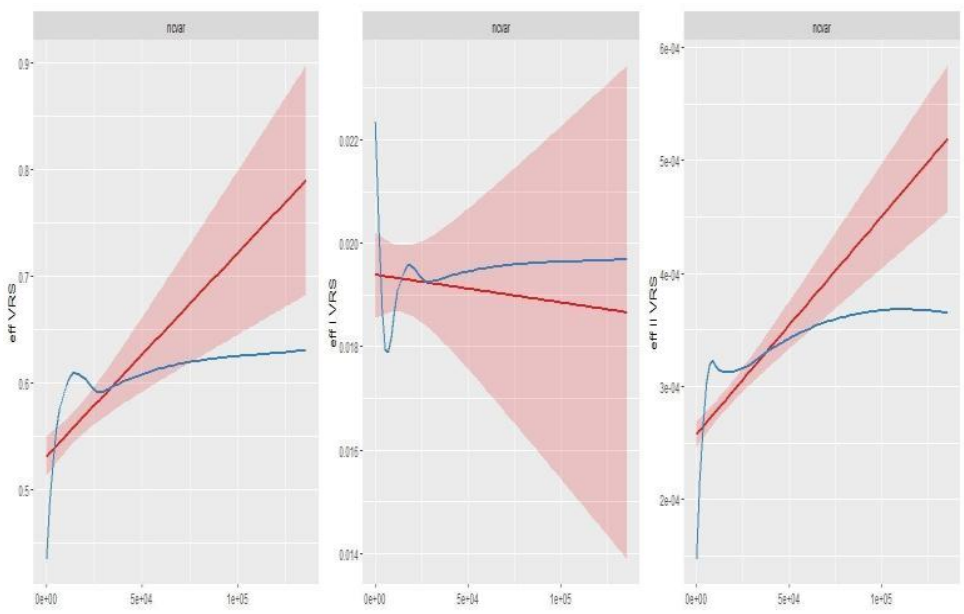

Figure 8. Relationship of the non-discretionary assumed variable to the efficiency of the system and its sub-processes in the case of the NDEA model with all relational variables assumed discretionary in the case of the assumption of scale returns variables in the model


Figure 9. Relation of the non-discretionary assumed variable to the efficiency of the system and its sub-processes in the case of the NDEA model where a relational variable is non-discretionary with assumption of variable scale returns in the model

In Figures 6, 7, 8 and 9, we report the graphical relationship between the non-discretionary variable (surgical interventions) and the relative efficiency measurements in the case of the four NDEA models as well as for all the subprocesses. For example, as can be seen in all the graphs, the non-discretionary variable has a positive relationship both with the relational efficiency of the entire system (graph on the left) and the efficiency of the second sub-process (graph on the right) (inclination positive of the red line o), except for the first sub-process (central graph) where the inclination is negative in all four measurements. Briefly summarised, the paper proposes the use of NDEA models as policy tools in which it is possible to introduce multi-objective preference systems to be translated into "discretionary/non-discretionary" assumptions of the variables. In the passage of the NDEA approach as a mere tool of efficiency measurement (NDEA 1) to more complex policy tool (model NDEA 2), it is necessary to specify that the measurements are not independent. The results of the correlation analyses are in Table 8, while the chi-square $\left(\chi^{2}\right)$ results (independence test) are presented in Table 9. 
Table 8. Correlation analysis

\begin{tabular}{ll}
\hline & $\begin{array}{l}\text { NDEA non come strumento di policy (NDEA 1) vs NDEA come strumento di } \\
\text { policy (NDEA 2) }\end{array}$ \\
\hline CRS & $\underline{0.9877}$ \\
\hline Correlazione & VRS \\
\hline Correlazione & $\underline{0.8706}$ \\
\hline
\end{tabular}

Table 9. Test chi-square

\begin{tabular}{|c|c|}
\hline & $\begin{array}{l}\text { NDEA non come strumento di policy (NDEA 1) vs NDEA come strumento di } \\
\text { policy (NDEA 2) }\end{array}$ \\
\hline Test chi-squared & CRS \\
\hline p-value & 0.0002174 \\
\hline $\begin{array}{l}\text { Statistical test }(\mathrm{df} \\
300300)\end{array}$ & $\begin{array}{l}\underline{303040} \\
(\alpha=0.05, \text { c.v. }=301575,9) \\
(\alpha=0.01, \text { c.v. }=302105,8)\end{array}$ \\
\hline & VRS \\
\hline $\mathrm{p}$-value & 0.02148 \\
\hline $\begin{array}{l}\text { Statistical test }(\mathrm{df} \\
277150)\end{array}$ & $\begin{array}{l}\underline{278660} \\
(\alpha=0.05, c . v .=278375.8) \\
(\alpha=0.01, c . v .=278884.9)\end{array}$ \\
\hline
\end{tabular}

As expected, the two measurements are not independent (we cannot accept the null hypothesis of independence in Table 9) and are, instead, linearly related to each other with even very high values (see Table 8). In our opinion, this would confirm that it is possible to incorporate policy considerations into the NDEA efficiency models in the form of a "discretionary-non-discretionary" mix without losing the original sense of measurement or performance measurement.

\subsubsection{Influence of External Factors}

In applied efficiency analysis works with DEA, the second stage analysis is very widespread (see for example (Simar \& Wilson, 2011)) in which efficiency scores are regressed on a set of factors/variables external to the production process that influence their efficiency (seefor example (Cellini, Pignataro, \& Rizzo, 2000) and (Liu, Lu, Lu, \& Lin, 2013) (Mariz, Almeidab, \& Aloisec, 2018) for an applied revised DEA literature). Our proposal has considered the combined use of NDEA models (Model 1 and Model 2) as a multi-objective policy tool in which there are two processes: the first concerning the pursuit of the efficiency objective and the second that of welfare (Model 2). Even in this case, we can certainly admit that there are external factors that influence the processes of pursuing the policy objectives in our proposal, the transition from pursuing the only objective of efficiency to that of pursuing multiple objectives together with that of efficiency is represented by the passage from Model 1 to Model 2; in with the first model (Model 1), we measure only relative efficiency, while with the second model (Model 2), we measure the performances of a system that pursues two objectives. There is a close correlation between the two measurements as shown in Tables 8 and 9. Structuring the second stage analysis with two independent multiple regression models (one for each measurement) would not take into account this correlation between the two measurements. The relational nature of each individual NDEA model then makes efficiency measurements at both system and subpart level closely related by generating correlations between the equations for individual sub-processes. To estimate the extent to which external factors influence the processes of pursuing objectives, we propose a second stage analysis with a two-equation econometric model, to highlight the effects of external factors in the transition from one model to another (with or without all the objectives). An example is the system (4) in which the first equation regresses the measurement of the relative performance with asimilar Model1 on a set of external factors that are supposed to 
influence the process of pursuing the efficiency objective, while the second equation uses as a dependent variable for the measurement with a second model similar to Model 2 and regresses it on a set of external variables partially different from the first to insert the influence of external factors that are supposed to influence the process of pursuing the second objective incorporated only in the NDEA 2 model.

$$
\left\{\begin{array}{c}
\theta_{N D E A 1}=\alpha_{1}+\alpha_{4} \text { var }_{2}+\alpha_{5} \text { var }_{3}+\varepsilon_{1} \\
\theta_{N D E A 2}=\beta_{1}+\beta_{1} \text { var }_{1}+\beta_{2} \text { var }_{2}+\beta_{3} \text { var }_{3}+\varepsilon_{2}
\end{array}\right.
$$

The first equation in the system (4) refers to the measurement of relative performance with the Model 1 model $\left(\theta_{N D E A 1}\right)$, ), i.e., the measurement of performance in the absence of the pursuit of the second objective. This equation considers the variables $\operatorname{var}_{2}$ e $\operatorname{var}_{3}$ as external factors that are supposed to influence the process of achieving the efficiency target. The variable var $_{1}$ is present only in the second equation as it is expected to influence the solo process of pursuing the welfare objective incorporated in Model 2 only. As stated above, the two measurements (and therefore the two equations) are not independent, and this circumstance can be captured in a SUR (Seemingly Unrelated Regressions) model (Zellner, 1962) in which correlation between the equations of the system (4) is assumed through the error terms. The results of the estimate of system 4 in the case of efficiency scores for the model with returns of constant scale are shown in Table 10.

Tabele 10. Second stage results

\begin{tabular}{|c|c|c|c|c|}
\hline & Estimates & Standard error & t-value & $\operatorname{Pr}(>|t|)$ \\
\hline \multicolumn{5}{|c|}{ Equation 1(modello NDEA 1) } \\
\hline Intercept & 0.6398 & $6.96385 \mathrm{e}-02$ & 9.17682 & $\begin{array}{l}<2 \mathrm{e}-16 \\
* * *\end{array}$ \\
\hline Var2 & $-3.52753 \mathrm{e}-05$ & $3.33708 \mathrm{e}-05-$ & 1.057070 .29094 & 0.29094 \\
\hline Var3 & $-2.28956 \mathrm{e}-03$ & $3.69415 \mathrm{e}-03-$ & -0.61978 & 0.53566 \\
\hline Var4 & $-6.86232 \mathrm{e}-06$ & $5.97316 \mathrm{e}-05-$ & -0.11489 & 0.90858 \\
\hline \multicolumn{5}{|c|}{$\begin{array}{lll}\text { SSR: } 17.31 & \text { MSE: } 0.0314 & \text { Root MSE: } 0.1774\end{array}$} \\
\hline \multicolumn{5}{|c|}{ Multiple R-Squared: 0.00287 Adjusted R-Squared: -0.002632 } \\
\hline \multicolumn{5}{|c|}{ Equation 2 (modello NDEA 2) } \\
\hline Intercept & $6.91763 \mathrm{e}-01$ & $1.02604 \mathrm{e}-01$ & 6.74207 & $\begin{array}{l}3.963 \mathrm{e}-11 \\
* * *\end{array}$ \\
\hline Var1 & $-3.76678 \mathrm{e}-04$ & $5.38338 \mathrm{e}-04-$ & -0.69970 & 0.48441 \\
\hline Var2 & $-3.58936 \mathrm{e}-05$ & $3.33980 \mathrm{e}-05-$ & -1.07472 & 0.28297 \\
\hline Var3 & $-2.17689 \mathrm{e}-03$ & $3.69938 \mathrm{e}-03-$ & -0.58845 & 0.55647 \\
\hline Var4 & $-7.46068 \mathrm{e}-06$ & $5.97654 \mathrm{e}-05-$ & -0.12483 & 0.90070 \\
\hline \multicolumn{5}{|c|}{ SSR: $17.300 \quad$ MSE: $0.0315 \quad$ Root MSE: .17750} \\
\hline \multicolumn{5}{|c|}{ Multiple R-Squared: 0.00369 Adjusted R-Squared: -0.0035} \\
\hline
\end{tabular}

In this example, it emerges that the factors external to the production process have negative influence(i.e., a positive change in them influences negative way the pursuit of the efficiency objective) on the process of pursuing the efficiency objective (i.e., the variables 2,3 and 4) all have a negative influence. The variable that is supposed to influence the process of pursuing the welfare objective alone (i.e., var 1) also has a negative influence on the measurement of organisational performance when the latter pursues the two objectives simultaneously. It should be noted that the estimates of all these parameters associated with variables 1,2,3 and 4 are not statistically significant. However, moving from the system with a single objective (first equation) to the one with two (second equation), the negative effect on the performance of var 2 and 3 remains substantially unchanged, contrary to what happens for var 
4 whose negative effect worsens performance in the presence of the system of two objectives. In the latter case, the effect of the correlation between the two equations by means of the most obvious error term.

\section{Discussion}

In this paper, we have proposed an innovative framework to deal with organisational policy preferences (understood as the identification, selection and pursuit of corporate objectives) within the frontier models for measuring performance (see Note 14) related to decision-making units modelled as a network of two interconnected processes (see Figures 1 and 2). In particular, our proposal provides for the use of the NDEA approach as a policy tool. The pursuit of organisational objectives is not dealt with in terms of trade-offs (Smith \& Street, 2005) but is translated into a discretionary-non-discretionary mix on the variables of an NDEA model. This allows us to measure organisational performances when the latter pursues its objectives. A simple application to the public health sector has identified its application potential. Our proposal has essential elements: 1) the identification of the organisational objectives and the related organisational policy variables to be included in an NDEA model, 2) the selection of the variables to be included in the NDEA model distinguishing the policy variables with a non-discretionary connotation from discretionary policy ones with the consequent construction of an NDEA model (section 2), and 3) data collection, the resolution of the NDEA model (s), the development of a decision-making process (we adopted one of a statistical nature (section 3)) and the second stage analysis to estimate the influence of external factors on performance measurements articulated as a structural system of non-independent equations. On this last point, our choice fell on a Seemingly-Unrelated-Regression (SUR) econometric model (Zellner, 1962). The fundamental motivation to structure the second stage in this way is that we are interested in estimating the effects of these factors when moving from one measurement to another with models that foresee different systems of objectives. expected that, in our example, the external factors that they influence the process of pursuing efficiency, they are the same in all measurements, but above all there are factors which, although not modelled, influence all measurements given the evident correlation between the latter. The main topic of the paper was also introduced starting from the reflections and observations on the use of relative efficiency measurement models such as DEA as policy tools provided in the work of (Smith \& Street, 2005). These two authors in their work cited how to deal with issues related to the use of DEA models (Cooper, Seiford, \& Tone, 2007) as policy tools, warning that these models are considered as a policy tool as regulators use them to modify the real behavior of organisations. Their use as policy tools is derived from the fact that, in the multiplicative version, the DEA models (Cooper, Seiford, \& Tone, 2007) can resolve policy issues by placing it as a trade-off between competing objectives. In these models, once the target variables have been collected in a vector of outputs, each of them will be associated with a weight whose optimal value is calculated base on the data. In addition, the DEA models model the production processes/organisations (but in general any decision-making unit) as inputs/outputs systems without specifying their internal structure. Our proposal seeks to take a step forward on the topic and propose the use of NDEA models as policy tools as much as happens for DEA models. NDEA models, such as DEA, are used to measure the relative technical efficiency of production processes, taking into account, and unlike what DEA does, their internal structure (for classification, see for example) and, at the same time, measure the relative efficiency of its parts (relational NDEA has been proposed by (Kao, 2009(a)) (Kao, 2014)). Other issues addressed in the paper of (Smith \& Street, 2005) concern issues such as the selection of variables to be included in these models. Our proposal has also affected this aspect by translating organisational policy preferences into NDEA models into a "discretionary/non-discretionary" mix of variables included in the model itself and, thus, does not treat organisational policy preferences in terms of trade-off between competing objectives as in DEA(Smith \& Street, 2005). In the DEA (Cooper, et al., 2007) approach, the treatment of variables as non-discretionary variables is not new. In our opinion, one of the original aspects of the proposal is treating the policy preferences within the NDEA methodology by exploiting the latter possibility created for the DEA models. One possible extension of the work is to define objectives at the sub-process level to apply the decomposition formula $($ Kao, 2014) and isolate its effects at the individual sub-process level. To the nest of our knowledge, dealing with policy issues within NDEA models by exploiting the assumption of non-discretion of variables is a way not yet addressed in the work of applied economics, managerial sciences and operational research. In our example application, this last assumption involved only one relational variable (surgical interventions) of the model, therefore, placing it as a target variable for the welfare objective. In the end, in our application, the entire system of policy preferences on the objectives translated into an NDEA model with a relational variable of a non-discretionary type and 4 discretionary variables (doctors, nurses, beds and technical-health personnel) (see Note 20). This mix expressed managerial policy preferences on two objectives: that of efficiency through the reduction of 4 discretionary variables and that of welfare while maintaining the target variable of surgical interventions as a proxy for accessing this type of service. The measurement with the NDEA model was, therefore, considered as a general 
performance measurement to achieve the set objectives. In other words, the unit that had earned a score of 1 implies an excellent performance by the organisation in pursuing its two objectives. For example, a score of 0.7 is interpreted as good but improved performance of $30 \%$ with only improvement in technical efficiency in the NDEA-CRS models. Instead always improved by $30 \%$ but also achievable the scale adjustments once eliminate technical efficiency, always looking at the effects/consequences/implications that these adjustments would have had on the pursuit of the other objective (the part of the tests). The measurement was, therefore, attributed to a wider value than the simple measurement of economic performance and technical efficiency. The aim of this study was to clarify the application potential of the approach. We hope to have succeeded in the intent. The approach can be generalised if: 1) several objectives are considered (grouped, for example, in categories like economic objectives such as efficiency, or social objectives such as welfare, or environmental objectives (see Note 21) such as the reduction of the production of waste or noise or air pollution, or of improvement or in any case not deterioration of the quality and so on), 2) if a mix of variables is adopted as wider and different "discretionary/non-discretionary", 3) if we consider a different productive sector of application (public or private that is the production of goods and services), 4) if we model more sub-processes (this is a point to be developed in future research), and finally 5) if we consider NDEA models with different input and output orientations (see Note 22) (adapting model 1A to specific application as happened for model 1). In the applied economic literature, the use of DEA as a policy tool has been proposed by some authors exploiting other possibilities that the methodology itself offers (some examples are in (Chilingerian \& Sherman, 1997)). All these authors, to our knowledge, do not consider the internal structure of a production process/organisation/decision-making unit but work directly on the weights of a DEA model production process/organisation/decision-making unit but work directly on the weights of a DEA model (note 18).

\section{Conclusion}

To conclude, we believe that an obvious advantage of the proposal is that it considers the internal structure of a production process and managerial objectives at sub-process level. However, the application has shown some delicate aspects of our approach, including: 1) knowledge of the production sector considered is fundamental in order to establish the policy objectives according to the logic of the mix of "discretionary/non-discretionary" variables, 2) the selection of a policy variable to be considered non-discretionary, but in general for the policy variables that you want to consider, it is closely linked to the production sector in which the organisation operates.. The innovative aspects of the paper, on the other hand, are that: 1) the researcher/manager can translate his policy preferences into a "discretionary/non-discretionary" mix of variables in an NDEA model and, 2) it is also possible to deal with policy objectives at sub-process level ( see Note 23).. The results of our simple application have shown some interesting things such as a trade-off between the pursuit of a further objective compared to that of efficiency pursued and measured in the NDEA models occurs when efficiency gains are assumed to be pursued through scale adjustments.

\section{References}

Aigner, D., Lovell, C., \& Schmidt, P. (1977). Formulation and estimation of stochastic frontier production functions. Journal of Econometrics, 6, 21-37. https://doi.org/10.1016/0304-4076(77)90052-5

Allen, R., Athanassoupoulos, A., Dyson, R., \& Thanassoulis, E. (1997). Weight Restrictions and Value Judgements in Data Envelopment Analysis: Evolution, Development and Future Directions. Annals of Operations Research, 73, 13-34. https://doi.org/10.1023/A:1018968909638

Castelli, L., \& Pesenti, R. (2014). Network, Shared Flow and Multi-level DEA Models: A Critical Review. In W. C. Zhu (Ed.), Data Envelopment Analysis, International Series in Operations Research \& Management Science (Vol. 208, pp. 329-366). New York: Springer Science+Business Media. https://doi.org/10.1007/978-1-4899-8068-7_15

Castelli, L., Pesenti, R., \& Ukovich, W. (2010). A classification of DEA models when the internal structure of the Decision Making Units is considered. Annals of Operations Research, 173, 207-235. https://doi.org/10.1007/s10479-008-0414-2

Castelli, L., Pesenti, R., \& Ukovicha, W. (2001). DEA-like models for efficiency evaluations of specialized and interdependent units. European Journal of Operational Research, 132(2), 274-286. https://doi.org/10.1016/S0377-2217(00)00151-X

Cellini, R., Pignataro, G., \& Rizzo, I. (2000). Competition and Efficiency in Health Care: An Analysis of the Italian Case. Internatinal Tax and Public Finance, 7, 503-519. https://doi.org/10.1023/A:1008737506560

Charnes, A., \& Cooper, W. (1962). Programming with Linear Fractional Functionals. Naval Research Logistics Quarterly, 2, 181-185. https://doi.org/10.1002/nav.3800090303 
Chen, Y., Cook, W. D., Li, N., \& Zhu, J. (2009b). Additive efficiency decomposition in two-stage DEA. European Journal of Operational Research, 196, 1170-1176. https://doi.org/10.1016/j.ejor.2008.05.011

Chilingerian, J., \& Sherman, H. (1997). DEA and Primary Care Physician Report Cards: Deriving Preferred Practice Cones from Managed Care Service Concepts and Operating Strategies. Annals of Operations Research, 73, 35-66. https://doi.org/10.1023/A:1018993515090

Cook, W. D., Zhu, J., Yang, F., \& Bi, G.-B. (2010). Network DEA: Additive efficiency decomposition. European Journal of Operational Research, 207(2), 1122-1129. https://doi.org/10.1016/j.ejor.2010.05.006

Cooper, W. W., Seiford, L. M., \& Tone, K. (2007). Data Envelopment Analysis. A Comprehensive Text with Models, Application, References and DEA-Solver Software. New York: Springer.

Fa“re, R. (1996b). Productivity and intermediate products: A frontier approach. Economics Letters, 50, 65-70. https://doi.org/10.1016/0165-1765(95)00729-6

Fa“re, R., \& Whittaker, G. (1995). An intermediate input model of dairy production using complex survey data. $J$ Agric Econ, 46, 201-213. https://doi.org/10.1111/j.1477-9552.1995.tb00766.x

Fare, R., \& Grosskopf, S. (2000). Network DEA. Socio-Economics Planning Sciences, 34(35-49). https://doi.org/10.1016/S0038-0121(99)00012-9

Fetter, R., \& Freeman, J. L. (1986). Diagnosis related groups: product linemanagement within hospitals. Academy of Management Review, 11(1), 41-54. https://doi.org/10.5465/amr.1986.4282622

Fetter, R., Shin, Y., Freeman, J. A., \& Thompson, J. (1980). Case mix definition by diagnosis related groups. Medical Care, 18(2), 1-53.

Health \& Ministry. (2016). Banca Dati del Servizio Sanitario Nazionale. Retrieved from http://www.salute.gov.it/portale/documentazione/p6_2_8_1_1.jsp?lingua=italiano\&id=6

Kao, C. (2009a). Efficiency decomposition in network data envelopment analysis: A relational model. European Journal of Operational Research, 192(949-962). https://doi.org/10.1016/j.ejor.2007.10.008

Kao, C. (2013). Dynamic data envelopment analysis: a relational analysis. Eur J Oper Res, 227, $325-330$. https://doi.org/10.1016/j.ejor.2012.12.012

Kao, C. (2014). Efficiency decomposition for general multi-stage systems in data envelopment analysis. European Journal of Operational Research, 232, 117-124. https://doi.org/10.1016/j.ejor.2013.07.012

Kao, C. (2014). Network data envelopment analysis: A review. European Journal of Operational Research, 239(1), 1-16. https://doi.org/10.1016/j.ejor.2014.02.039

Kao, C., \& Hwang, S.-N. (2008). Efficiency decomposition in two-stage data envelopment analysis: An application to non-life insurance companies in Taiwan. European Journal of Operational Research, 185(418-429). https://doi.org/10.1016/j.ejor.2006.11.041

Kawaguchi, H., Tone, K., \& Tsutsui, M. (2014). Estimation of the efficiency of Japanese hospitals using dynamic and network Data envelopment Analysis model. Health Care Management Sciences, 17, 101-112. https://doi.org/10.1007/s10729-013-9248-9

Liu, J., Lu, L., Lu, W.-M., \& Lin, B. (2013). A survey of DEA applications. Omega, 41, 893-902. https://doi.org/10.1016/j.omega.2012.11.004

Mariz, F., Almeidab, M., \& Aloisec, D. (2018). A review of Dynamic Data Envelopment Analysis: state of the art and applications. Intl. Trans. in Op. Res., 25, 469-505. https://doi.org/10.1111/itor.12468

Pinto, C. (2016, March). The Acute Care Services Production Process's Efficiency: A DEA Network Model for the Italian Hospitals. Athens Journal of Health, 3(1). https://doi.org/10.30958/ajh.3-1-2

Rabar, D. (2017). An overview of data envelopment analysis application in studies on the socio-economic performance of OECD countries. Economic Research, 30(1), 1770-1784. https://doi.org/10.1080/1331677X.2017.1383178

Rebba, V. (2006). Measuring Hospital Efficiency through Data Envelopment Analysis when Policy-makers' Preferences Matter. An Application to a sample of Italian NHS hospitals. Working Paper (13 /WP/2006). Department of Economics-Ca' Foscari Un iversity of Venice. https://doi.org/10.2139/ssrn.946885 
Seiford, L., \& Zhu, J. (1999). Profitability and marketability of the top 55 US commercial banks. Management Sciences, 45, 1270-1288. https://doi.org/10.1287/mnsc.45.9.1270

Seiford, L., \& Zhu, J. (2002). Modeling undesirable factors in efficiency evaluation. European Journal of Operational Research, 142, 16-20. https://doi.org/10.1016/S0377-2217(01)00293-4

Sexton, T., \& \& Lewis, H. (2003). Two-stage DEA: An application to Major League Baseball. Journal of Productivity Analysis, 19(2), 227-249. https://doi.org/10.1023/A:1022861618317

Shrime, M., Mukhopadhyay, S., \& Alkirea, B. (2018). Health-system-adapted data envelopment analysis for decision-making in universal health coverage. Bull World Health Organ, (96), 393-401. https://doi.org/10.2471/BLT.17.191817

Simar, L., \& Wilson, P. (2011). Two-stage DEA: caveat emptor. J Prod Anal, 36, 205-218. https://doi.org/10.1007/s11123-011-0230-6

Smith, P., \& Street, A. (2005). Measuring the Efficiency of Public Services:The Limits of Analysis. Journal of the Royal Statistical Society, 168(2), 401-417. https://doi.org/10.1111/j.1467-985X.2005.00355.x

Stone, M. (2002). How not to measure the efficiency of public services (and how one might). Journal of the Royal Statistical Society, 165(3), 405-422. https://doi.org/10.1111/1467-985x.02461

Yang, Z. (2006). A two-stage DEA model to evaluate the overall performance of Canadian life and health insurance companies. Mathematical and Computer Modeling, 123(1), 105-124. https://doi.org/10.1016/j.mcm.2005.12.011

Zellner, A. (1962). An efficient method of estimating seemingly unrelated regression equations and tests for aggregation bias. Journal of the American Statistical Association, 57(298), 348-368. https://doi.org/10.1080/01621459.1962.10480664

\section{Notes}

Note 1. DEA used to build global index to relative performances measurement as well as there are applications to macro level as for example happen in. (Shrime, Mukhopadhyay, \& Alkirea, 2018), for a more recent review (Rabar, 2017).

Note 2. (Smith \& Street, 2005) discussesalso their assumptions and utility for public services regulators.

Note 3. For authors others controversial areas are: 1) which external factors to be considered, and 2) how to treat dynamic effects, in other words how past decisions and future investment are relevant in the performcances measurements.

Note 4. In their paper, the authors highlight the comparison between overall performance measures and specific performance measures. Developing global efficiency measures (Stone, 2002), consider parameter models such as Stochastic Frontier Analysis (SFA) (Aigner, Lovell, \& Schmidt, 1977), and not parametric primarily such as Data Envelopment Analysis (DEA) (Cooper, Seiford, \& Tone, 2007)

Note 5. As noted in (Castelli, Pesenti, \& Ukovich, 2010) in the case of shared inputs and/or outputs shared between sub-processors. Exogenous input is offered from outside to a system.

Note 6. When considering the internal structure of a production process to measure relative efficiency, different approaches can be used: 1) measure the relative efficiency independently of all sub-processes and then aggregate them into an additive or multiplier manner or 2) use the NDEA connection models proposed in (Fare \& Grosskopf, 2000) (Fa"re \& Whittaker, 1995) (Fa"re R. \&., 1996b), where you can take into account the operations between processes but you can't use a multiplication formula because the variables get different weights. Other NDEA models involve additive decomposition as those in (Chen, Cook, Li, \& Zhu, 2009b), (Cook, Zhu, Yang, \& Bi, 2010)) instead of multiplier decomposition as happen in (Kao, 2009(a)) e (Kao, 2014)

Note 7. So you can treat it as a linear programming problem and solve it using the lp function of the lpSolve package in R [Michel Berkelaar and others (2015). lpSolve: Interface to 'Lp_solve'v. 5.5 to Solve Linear/Integer Programs. R package version 5.6.13. https://CRAN.R-project.org/package=lpSolve]

Note 8. Variable return to scale model require a scalar in the objective function and in the constraints (see (Cooper, Seiford, \& Tone, 2007) for DEA standard models)

Note 9. This setting of (Smith \& Street, 2005), as you can read, it's a macro type 
Note 10. Hospital services are considered of great social value

Note 11. Hospital health services can then be classified as ordinary, in day hospital or in day surgery.

Note 12. www.salute.gov.it. Banca Dati del Servizio Sanitario Nazionale.

Note 13. Case mix index (CMI) is a relative value assigned to a diagnosis-related group of patients in a medical care environment. The CMI value is used in determining the allocation of resources to care for and/or treat the patients in the group (Fetter, Shin, Freeman, \& Thompson, 1980) (Fetter, Freeman, \& J.L., 1986).

Note 14. We prefer to talk about performance in a more general sense of efficiency because now the measurement is conducted with an efficiency model but involves more dimensions than the single dimension of resource use efficiency.

Note 15. As we have repeatedly specified, we are not interested in the decomposition of efficiency because the purpose of the paper is only to show a proposal. But obviously this does not exclude that the impact of the pursuit of the objectives does not have an effect also at the sub-process level.

Note 16. The inefficient units inside the correspondent regions should project themself on the efficient frontier.

Note 17. Decisions to pursuit these two objectives and adopt scale adjustments

Note 18. In the hospital sector a proxy variable of quality of care could be the reduction of hospitalisation days. This means that in our application we could also consider a third hospital health policy objective, which is the quality of acute care, and therefore consider our second relational variable "days of hospitalization" as a policy variable. The resulting system of objectives would have had three objectives: to improve the efficiency of the process (efficiency, technical and scale objective), not to reduce access to hospital surgical services (welfare objective) and finally to improve the quality of care for acute cases under ordinary regimen by reducing the number of days of hospitalization for this category of patients (quality of care objective). Alternatively, increasing total discharges with the same resources employed might also have been considered a welfare objective, but obviously this would have required an output orientation of the NDEA model.

Note 19. Here by "general performance" we mean the ability to achieve the following objectives

Note 20. If the orientation of the model had been to the output the policy variables could have been an example all those inserted in the model output vector.

Note 21. For example, in the DEA methodology it is possible to accommodate so-called "bad" variables ( esempio in (Seiford \& Zhu, 2002))

Note 22. It should be noted that NDEA models also have a dynamic version (Kao, 2013).

Note 23. Here we refer to the possibility to solve several DEA model one for each sub-process indipendently one from each other. 